\title{
A Comparative Clinical Study between X-ray Nasopharynx and Nasal Endoscopy in the Diagnosis of Chronic Adenoiditis: Our Experience
}

\author{
Anoop Muraleedhara Ghosh ${ }^{1}$, Shobhit Gupta ${ }^{2}$, Amarveer S Mehta $^{3}$
}

\begin{abstract}
Aims and objectives: In our study, we tried to analyze the utility of X-ray nasopharynx and nasal endoscopy in assessing the size of the adenoid tissue and thereby grading chronic adenoiditis. The grading of adenoids was correlated clinically with the severity of symptoms attributed to chronic adenoiditis.

Materials and methods: Our study was an observational prospective study of 80 children with a diagnosis of chronic adenoiditis conducted in the Dept of ENT from January 2019 to 2020. The digital X-ray nasopharynx lateral view and nasal endoscopic results of all patients were analyzed, graded, and compared.

Results: The most common age group was 5-7 years which included 34 children (42.5\%). Mean adenoid-nasopharyngeal ratio for which otitis media with effusion (OME) was present was 0.72 which corresponds to X-ray grade II. It was also noticed that $71.4 \%$ X-ray grade III had OME and $65.8 \%$ of cases of endoscopic grade III adenoid had OME.

Conclusion: X-ray nasopharynx was found to be a simple, less costly, practically easy option in a day-to-day practice in assessing the size of adenoid tissue; whereas nasal endoscopy is a more scientific approach providing three-dimensional views of the adenoids in the nasopharyngeal compartment. Lateral extensions of adenoids to eustachian tube orifices can be noticed in nasal endoscopy. Nasal endoscopy is considered the gold standard in diagnosing chronic adenoiditis. Reaching the correct diagnosis of chronic adenoiditis at the earliest is the main key in treatment to prevent complications and sequelae related to this clinical condition.

Clinical significance: Both X-ray nasopharynx and nasal endoscopy are useful tools in the diagnosis of chronic adenoiditis. Grading of adenoids can be done in both techniques. While X-ray tomogram is a cheap and convenient method, nasal endoscopy is more scientific and accurate in giving a three-dimensional view of adenoids.

Keywords: Adenoid-nasopharyngeal ratio, Chronic adenoiditis, Nasal endoscopy, Otitis media with effusion, X-ray nasopharynx.

Clinical Rhinology An International Journal (2020): 10.5005/jp-journals-10013-1373
\end{abstract}

\section{INTRODUCTION}

The nasopharyngeal tonsil is commonly known as adenoids. It is situated at the junction of the roof and posterior wall of the nasopharynx. It is composed of vertical ridges of lymphoid tissue separated by deep clefts. The lymphoid tissue forming future adenoid can be identified at 4-6 weeks of gestation. The adenoid can be identified by MRI scan from the age of 4 months in $18 \%$ of children. Growth of adenoids continues rapidly during infancy and plateaus between 2 and 14 years of age. Regression of adenoids occurs after 15 years of age in most children ${ }^{1}$ (Fig. 1). Recurrent attacks of rhinitis, sinusitis, chronic tonsillitis, and allergy lead to adenoid hypertrophy and chronic adenoiditis. Children present with mouth breathing, nasal obstruction, epistaxis, sleep apnea, nocturnal enuresis, hearing loss, and rarely pulmonary hypertension and cor pulmonale.

The term adenoid was coined by Wilhelm in 1870. The first clinical description of adenoids dated back to AD 640. It was Paul of Aegina who was credited with the treatment of adenoids for the first time. The projections in the nasal space and upper throat were surgically removed using a ligature passed transnasally. This is the earliest description of surgery on the adenoids. ${ }^{2}$

Adenoidectomy was performed in the modern era by William Meyer in 1867, using a ring knife through the nasal cavity. The term adenoid facies was coined by CV Tomes in 1872. Dentofacial changes associated with nasal airway blockage have been described

\begin{abstract}
1,2ENT Department, FH Medical College and Hospital, Etmadpur, Uttar Pradesh, India

${ }^{3}$ Department of Community Medicine, FH Medical College and Hospital, Etmadpur, Uttar Pradesh, India

Corresponding Author: Shobhit Gupta, ENT Department, FH Medical College and Hospital, Etmadpur, Uttar Pradesh, India, Phone: +91 8279984617, e-mail: Shobhitsrms@gmail.com

How to cite this article: Ghosh AM, Gupta S, Mehta AS. A Comparative Clinical Study between X-ray Nasopharynx and Nasal Endoscopy in the Diagnosis of Chronic Adenoiditis: Our Experience. Clin Rhinol An Int J 2020;13(1):9-14.
\end{abstract}

Source of support: Nil

Conflict of interest: None

as adenoid facies by him. He coined the term based on his belief that enlarged adenoids were the principal cause of airway obstruction and resulted in significant dentofacial morphological change. ${ }^{3}$

There are still concerns in the literature regarding the best way to diagnose adenoid hypertrophy in pediatric populations. ${ }^{4}$

There are different objective modalities for the assessment of adenoid hypertrophy. Mirror examination, digital palpation, lateral view of X-ray nasopharynx, and nasal endoscopy are few to list. Each modality has its own merits and demerits.

Since older days, X-ray nasopharynx lateral view is an effective tool in assessing adenoid size. It is simple, less costly, 


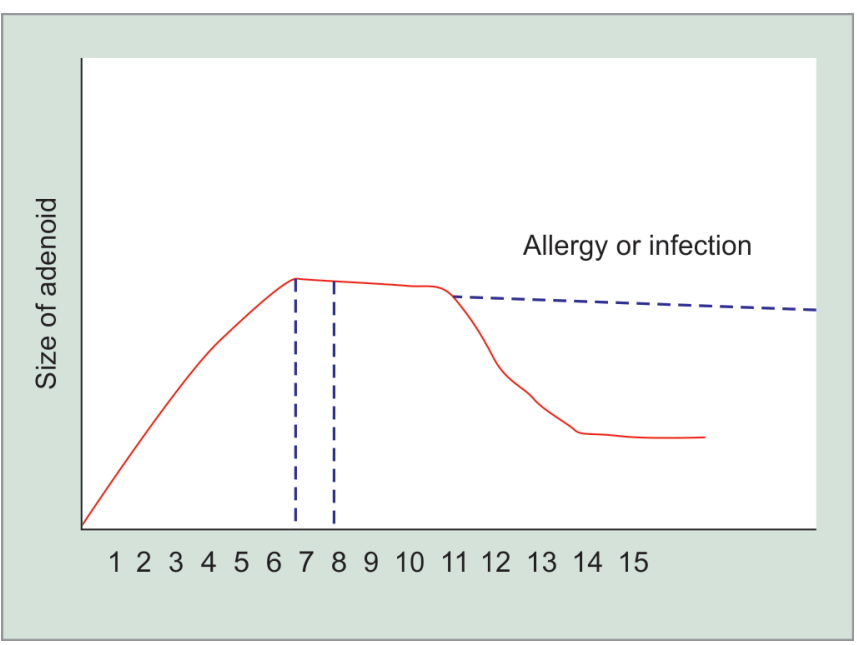

Fig. 1: Relation between age and size of adenoid

readily available, and reproducible. In a comparative study of different methods of adenoid size measurement on lateral neck X-rays, Wormald and Prescott concluded that the Cohen and Konak method showed the highest positive predictive value and considered to be a useful diagnostic tool in the pediatric population with adenoid hypertrophy. ${ }^{5}$

Mean nasopharyngeal depth and mean adenoid depth were calculated as per the Yusuf et al. method. Adenoid-nasopharyngeal ratio (ANR) was calculated by dividing adenoid depth by nasopharyngeal depth. Fujioka et al. in 1979 described ANR for the first time. It is still followed the world over for measurement of adenoid size in X-ray nasopharynx lateral view.

An ANR of 0.7 and $>0.7$ is subjectively judged to have adenoid hypertrophy. There are few demerits associated with lateral neck films like the exposure of the child to radiation, technical issues relating to X-ray films, generation of a two-dimensional image form a three-dimensional structure, rotation of the skull, and inspiration or phonation during $\mathrm{X}$-ray examination could result in misinterpretation. ${ }^{6}$

Nasal endoscopy is presently considered as the standard method for assessment of adenoid size in several studies. It provides direct visualization of the nasopharynx. It helps in determining the size of the adenoid and the degree of obstruction at the level of the posterior choana. Nasal endoscopy gives objective and highly accurate results that correlate clinically with the severity of the adenoid hypertrophy than X-ray nasopharynx..$^{7-9}$ It is a reliable technique, reproducible, and safe. There is no exposure to radiation. Mostly nasal endoscopy can be done on an OPD basis. But at times an uncooperative child needs sedation in the operation theater.

In our institute, there was a high volume of cases pertaining to chronic adenoiditis for the last few years. This rise in chronic adenoiditis may be due to urbanization, environmental pollution, and allergy. So, we took this clinical study to know the merits and demerits of both X-ray nasopharynx and nasal endoscopy for the evaluation of adenoid size.

\section{Materials and Methods}

The present clinical study was conducted in the department of ENT, FH Medical College, Agra, Uttar Pradesh, India. The study period was of 1-year duration from January 2019 to January 2020. Our study was an observational prospective study of 80 children with a clinical

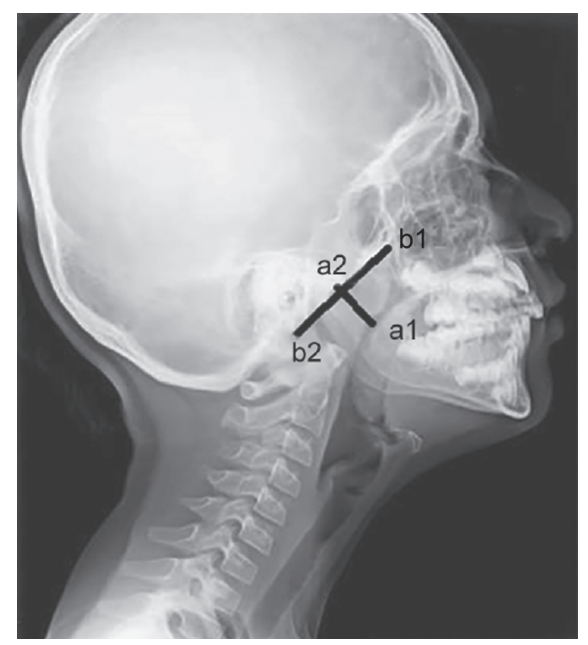

Fig. 2: X-ray nasopharynx showing adenoidal measurements. $a_{1}-a_{2}$ shows adenoidal length; $b_{1}-b_{2}$ shows nasopharyngeal length

diagnosis of chronic adenoiditis. Children in the age group 3-12 years with clinical and radiological features of chronic adenoiditis were included in the study. Children $<3$ and $>12$ years were not included. Children with past history of adenoidectomy, genetic disorder like Down's syndrome, cerebral palsy, congenital heart disease, nephrotic syndrome, cleft palate, chronic suppurative otitis media (CSOM), and congenital ear deformities were excluded. Each patient's clinical proforma was prepared which included detailed history, clinical examination, X-ray nasopharynx, nasal endoscopy, and oto-endoscopy to visualize the status of tympanic membrane (TM). Digital X-ray nasopharynx (lateral view) of all children were analyzed to calculate ANR and accordingly X-ray grading was noted.

The adenoidal measurement is done by noting the distance from the point of maximal convexity adenoid shadow ( $\mathrm{a}_{1}$-Fig. 2 ) anteroinferiorly to the anterior margin of basi-occiput ( $a_{2}$-Fig. 2).

The nasopharyngeal measurement is done by noting the distance between the anterior border and posterior border of the spheno-basi-occiput-synchondrosis $\left(b_{1}-b_{2}\right.$ Fig. 2$)$. Adenoidnasopharyngeal ratio was calculated and adenoid hypertrophy was graded as follows:

Grade 0 -No adenoid enlargement (0.0-0.25).

Grade I-Minimal enlargement (0.26-0.50).

Grade II-Moderate enlargement (0.51-0.75).

Grade III-Gross enlargement (0.76-1.00).

All patients were subjected to nasal endoscopy after application of nasal packs soaked in $4 \%$ lignocaine mixed with four ampoules adrenaline. Most of the children underwent nasal endoscopy on an OPD basis. Rarely nasal endoscopy was performed in an operation theater under sedation. $0^{\circ}$ pediatric nasal endoscope with diameter $2.7 \mathrm{~mm}$ was used in children $<6$ years whereas $0^{\circ}$ nasal endoscope with diameter $4 \mathrm{~mm}$ was used in children $>6$ years. Adenoid grading was done using the grading system proposed by Clemens and McMurray (Fig. 3).

Grade I-Adenoid tissue filling one-third of the vertical portion of the choanae.

Grade II-Adenoid tissue filling one-third to two-third of the choanae.

Grade III-Adenoid tissue filling two-third to nearly complete obstruction of the choanae.

Grade IV-Complete choanal obstruction. 


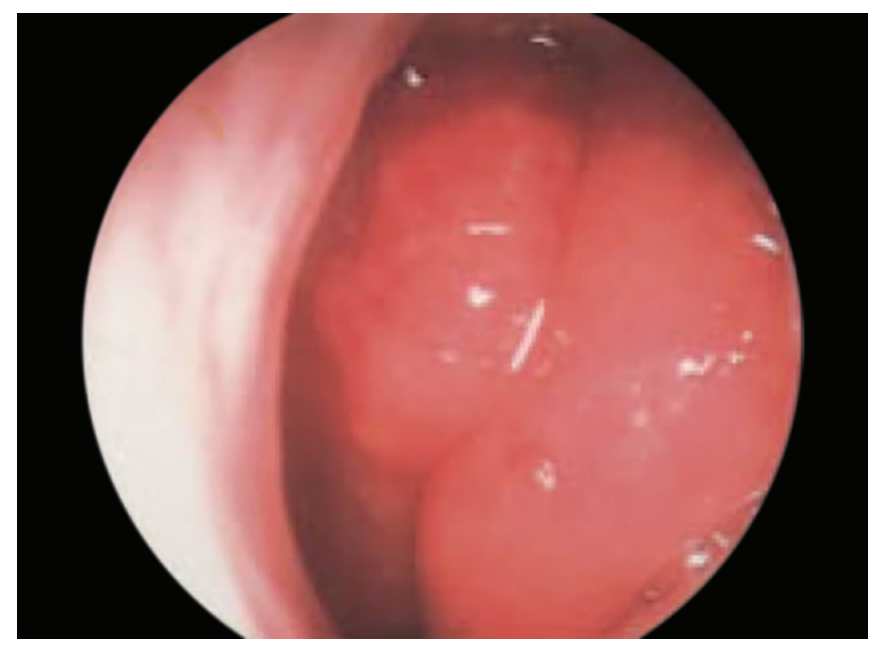

Fig. 3: Nasal endoscopy picture of adenoids

\section{Results}

The results of our present clinical study are briefly mentioned below-

- The age distribution of children with chronic adenoiditis showed higher incidents among $5-7$ years (42.5\%) followed by $3-5$ years (22.5\%).

- The sex distribution showed higher takes in males (60\%) than females (40\%).

- Forty-three children had adenoid facies (53.75\%).

- The TM was normal in 35 cases (43.75\%). It was dull and retracted in 24 cases (30\%). It was dull and bulging in 21 cases (26.25\%).

- The ANR of 0.72 was found to be significant. Fifty-one children (63.75) among 80 had otitis media with effusion (OME) with a mean ANR of 0.7221 .

- Fifty-seven children had grade II in X-ray nasopharynx which amounted to $71.25 \%$. Twenty-one children had grade III in X-ray nasopharynx (26.25\%).

- Thirty-six children had OME among a total of 57 grade II adenoids.

- Fifteen (71.4\%) children had OME among a total of 21 grade III.

The findings of our clinical study are shown in Tables 1 to 9 and Figures 4 to 9.

\section{Discussion}

The scientific analysis of our clinical study showed that both X-ray nasopharynx lateral view and nasal endoscopy are useful tools for the assessment of adenoid size. But nasal endoscopy is a bit superior in terms of its direct visualization of the adenoid tissue and the three-dimensional picture given by it.

As shown in many recent studies, the number of OME and the number of children with sleep apnea climbed the ladder up as the adenoid grading increased to grade III and grade IV in nasal endoscopy. Comparatively in grade II and grade III in X-ray nasopharynx. Recent study in Nigeria in 2010 by Orji et al. on children with OME found a significant association between type B tympanogram and the presence of significant (grade IV) nasopharyngeal obstruction. ${ }^{10}$

The mean ANR in the present study was 0.72 , which correlates with grade Il adenoid grading in X-ray nasopharynx and the number
Table 1: Age distribution

\begin{tabular}{llc}
\hline Age group (years) & No. of cases & Percentages \\
\hline$>3-5$ & 18 & 22.5 \\
$>5-7$ & 34 & 42.5 \\
$>7-9$ & 13 & 16.25 \\
$>9-11$ & 10 & 12.5 \\
$>11-12$ & 5 & 6.25 \\
Total & 80 & 100 \\
\hline
\end{tabular}

Table 2: Sex distributions

\begin{tabular}{lll}
\hline Sex & No. of cases & Percentage \\
\hline Male & 48 & 60 \\
Female & 32 & 40 \\
Total & 80 & 100 \\
\hline
\end{tabular}

Table 3: Adenoid facies

\begin{tabular}{llc}
\hline Adenoid facies & No. of cases & Percentage \\
\hline Present & 43 & 53.75 \\
Absent & 37 & 46.25 \\
Total & 80 & 100 \\
\hline
\end{tabular}

Table 4: Tympanic membrane appearance

\begin{tabular}{lll}
\hline Tympanic membrane & No. of cases & Percentage \\
\hline Normal & 35 & 43.75 \\
Dull and retracted & 24 & 30 \\
Dull and bulging & 21 & 26.25 \\
Total & 80 & 100 \\
\hline
\end{tabular}

Table 5: Comparison of adenoidal-nasopharyngeal ratio (ANR) with OME

\begin{tabular}{llll}
\hline OME & No. of cases & Mean & Percentage \\
\hline Present & 51 & 0.7221 & 63.75 \\
Absent & 29 & 0.6857 & 36.25 \\
Total & 80 & & 100 \\
\hline
\end{tabular}

Table 6: X-ray grading distribution

\begin{tabular}{llcc}
\hline ANR & $X$-ray grading & No. of cases & Percentage \\
\hline $0-0.25$ & 0 (no enlargement) & 0 & 0 \\
$0.26-0.50$ & 1 (minimal enlargement) & 2 & 2.5 \\
$0.51-0.75$ & 2 (moderate & 57 & 71.25 \\
& enlargement) & & \\
$0.76-1.00$ & 3 (gross enlargement) & 21 & 26.25 \\
Total & & 80 & 100 \\
\hline
\end{tabular}

of cases with OME. The mean ANR of the age group 5-7 years was 0.7361 and that of age group 7-9 years was 0.7314 . It went down to 0.682 in the age group of 9-11 years, which correlates with the study by Fujioka et al. ${ }^{11}$

It is observed that the number of cases with OME was not small in children with lower grades of adenoid size (grade I in $\mathrm{X}$-ray nasopharynx). This could be due to the lateral extension of adenoid tissue in to eustachian tubal orifice irrespective of the size of adenoid. Wright et al. studied the importance of nasal endoscopy 
Table 7: OME and X-ray grading

\begin{tabular}{llcl}
\hline X-ray grades & OME & No OME & Total cases \\
\hline Grade 0 & 0 & 0 & 0 \\
Grade I & 0 & $2(100 \%)$ & 2 \\
Grade II & $36(63.2 \%)$ & $21(36.8 \%)$ & 57 \\
Grade III & $15(71.40 \%)$ & $6(28.6 \%)$ & 21 \\
Total & 51 & 29 & 80 \\
\hline
\end{tabular}

Table 9: Adenoid hypertrophy: X-ray and endoscopic grades

\begin{tabular}{|c|c|c|c|c|c|}
\hline \multirow[b]{2}{*}{$X$-ray grade } & \multicolumn{4}{|c|}{ Endoscopic grade } & \multirow[b]{2}{*}{ Total } \\
\hline & I & II & III & IV & \\
\hline I & $2(100 \%)$ & 0 & 0 & 0 & 2 \\
\hline II & $9(15.8 \%)$ & $24(42.1 \%)$ & $21(36.8 \%)$ & $3(5.3 \%)$ & 57 \\
\hline III & 0 & $3(14.3 \%)$ & $17(81 \%)$ & $1(4.7 \%)$ & 21 \\
\hline Total & 11 & 27 & 38 & 4 & 80 \\
\hline
\end{tabular}
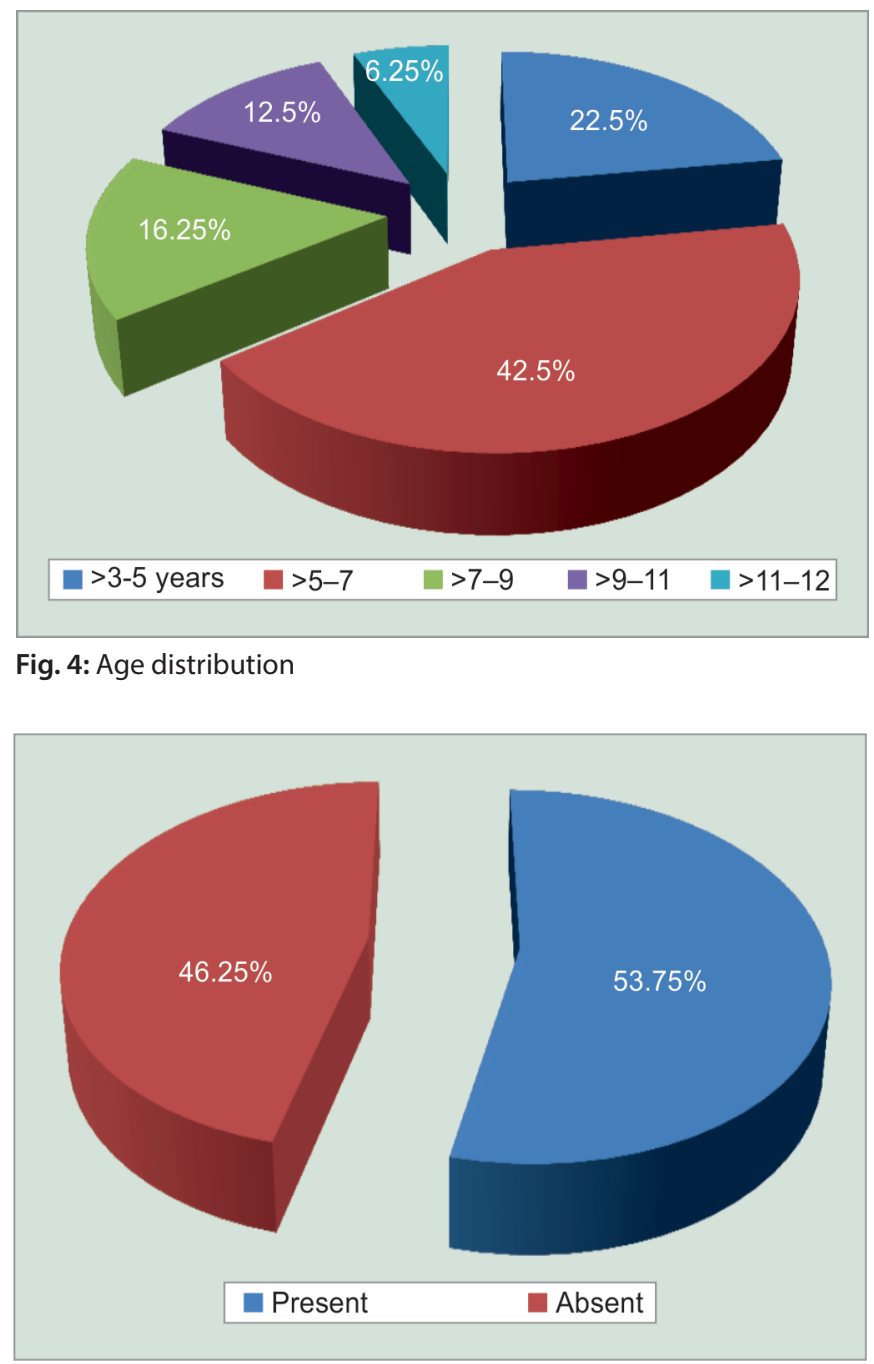

Fig. 6: Adenoid facies

in the assessment of adenoidal enlargement in lateral direction rather than anterior direction which is often missed in routine X-ray nasopharynx. ${ }^{12}$
Fig. 4: Age distribution
Table 8: OME and endoscopic grade

\begin{tabular}{llll}
$\begin{array}{l}\text { Endoscopic } \\
\text { grade }\end{array}$ & OME & No OME & Total cases \\
\hline Grade I & $4(36.4 \%)$ & $7(63.6 \%)$ & 11 \\
Grade II & $19(70.4 \%)$ & $8(29.6 \%)$ & 27 \\
Grade III & $25(65.8 \%)$ & $13(34.2 \%)$ & 38 \\
Grade IV & $3(75 \%)$ & $1(25 \%)$ & 4 \\
Total & 51 & 29 & 80 \\
\hline
\end{tabular}

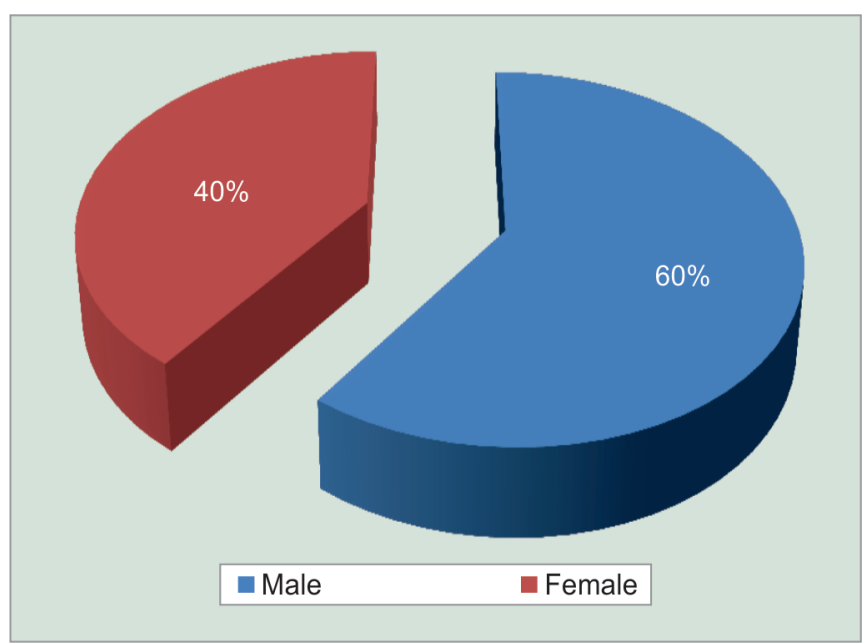

Fig. 5: Sex distribution

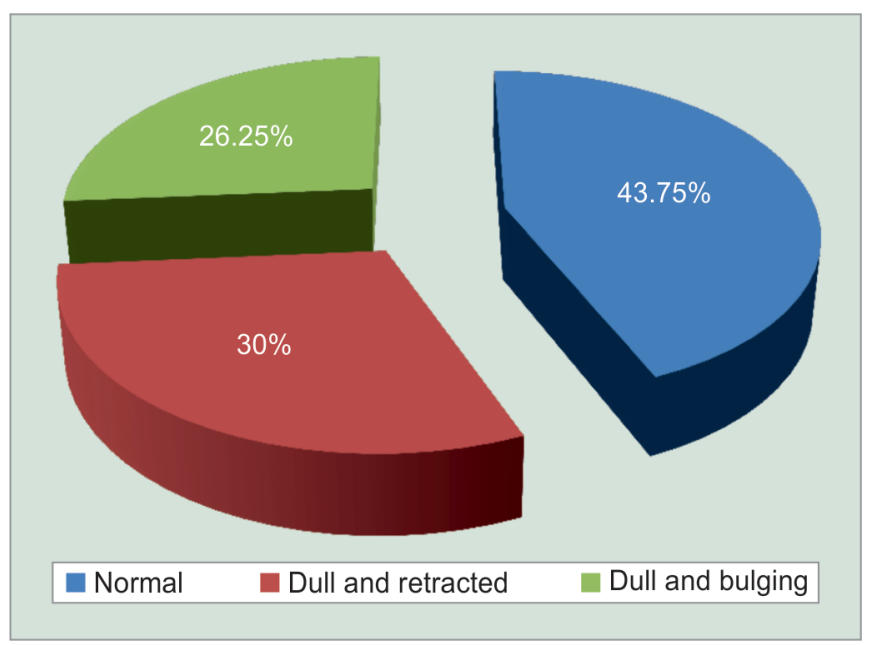

Fig. 7: Tympanic membrane appearance

In our study, the author noticed that $15.8 \%$ of patients with X-ray grade II were in endoscopic grade I, and $36.8 \%$ of patients in $\mathrm{X}$-ray grade II were in endoscopic grade III. This variation in grading 


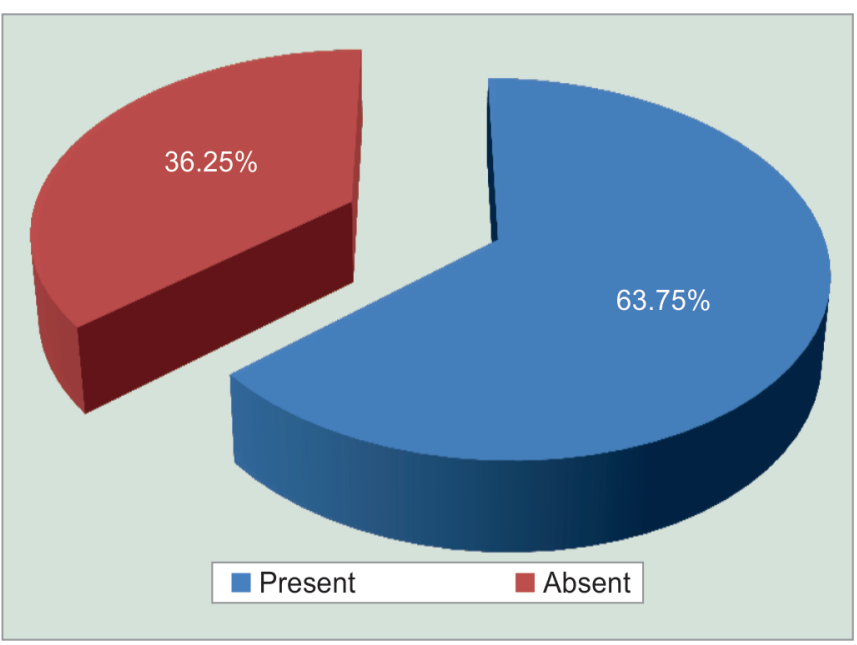

Fig. 8: Comparison of adenoidal nasopharyngeal

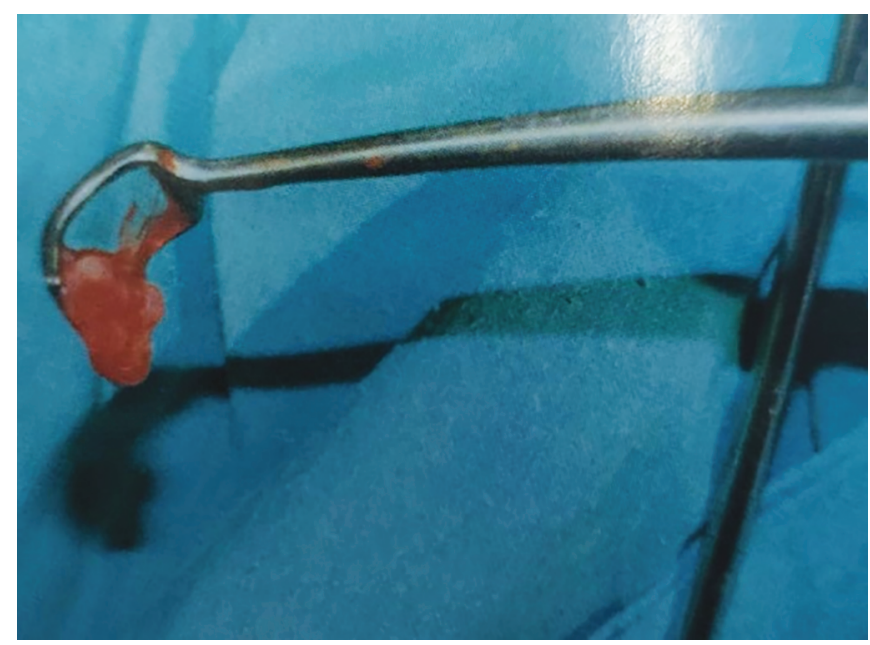

Fig. 10: Peroperative picture of excised adenoids

would be due to factors like lack of standardization of X-ray, the two-dimensional picture offered by X-ray, effects of positional change and respiratory movements noted in pediatric population. All these are parameters which affect the grading of adenoids by plain X-ray. Cohen et al. in their study supported the inaccuracy of $\mathrm{X}$-ray nasopharynx in assessing the adenoid size. They found poor correlation between the plain X-ray and the size of adenoids at operation $^{13}$ (Fig. 10).

Nasal endoscopy was more correlative, reliable, safe, reproducible, and easily tolerated with three-dimensional views. In our study, evaluation by endoscope was more correlative regarding the size of adenoids compared to plain X-ray. Our results were supported by studies by Yilmaz et al., Kinderman et al., and other colleagues in the assessment of adenoid size. ${ }^{14,15}$

\section{Conclusion}

We in our present clinical study found that both X-ray nasopharynx (lateral view) and nasal endoscopy were effective tools in assessing the adenoid size. X-ray nasopharynx is a better option in small clinical setups and is convenient. It is cheaper and suits poor economic states in Indian populations. Nasal endoscopy is a more

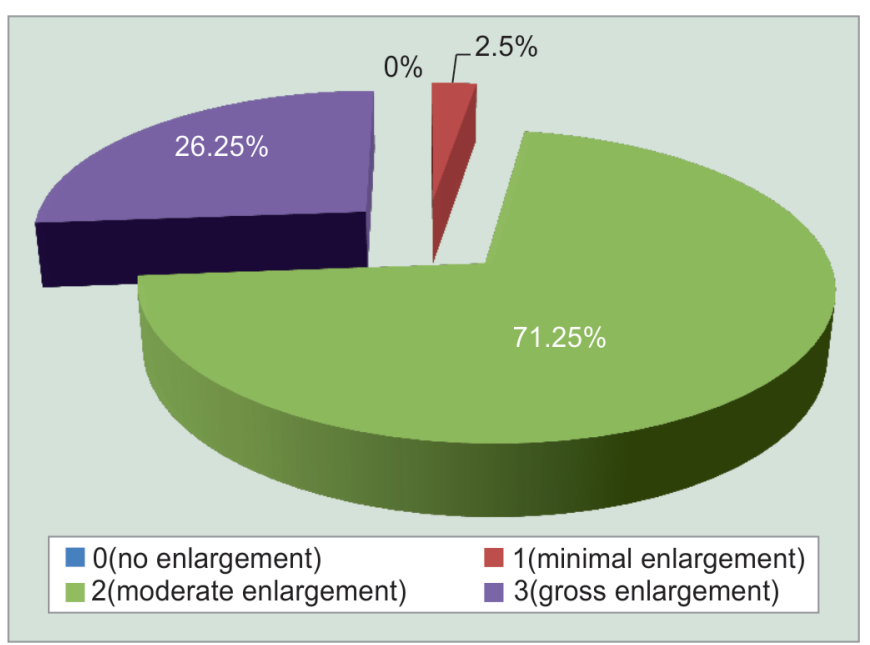

Fig. 9: X-ray grading distribution

scientific option. It is accurate and is considered the gold standard in assessing adenoid hypertrophy.

The number of children with OME increased as the grading of adenoid increased from grade I to grade II in X-ray grading; from grade I to grade III and grade IV in nasal endoscopy grading. Mean ANR of 0.72 is considered as significant pathological enlargement and such children has to be sent for audiometric evaluation.

There is a rise in the number of children with chronic adenoiditis in recent years. This could be due to an increase in environmental pollution, urbanization, modern food habits, and obesity in children.

Reaching an early diagnosis of chronic adenoiditis is important to prevent its complications and sequelae.

\section{ACKNOWLedgments}

We are thankful to the chairman and management of $\mathrm{FH}$ medical college, Agra for allowing us to conduct our study in this institute.

We thank Dr. Gaurav Khandelwal (Professor and Head, Dept. of ENT) and Dr. Anuj K Goel (Professor) for their constant support and guidance throughout the study period.

\section{Clinical Significance}

As described above, the children presenting with the features of chronic adenoiditis are on the rise. So reaching the current diagnosis at the earliest is very important for planning proper treatment, thereby avoiding complications and sequelae. Assessing the size of adenoids is crucial in treatment. Both grading system of X-ray nasopharynx and endoscopic grading are a useful tool in assessing the size of adenoids. Both have its own merits and demerits. X-ray tomography invented by Sir Roentgen in 1895 is still a cheap, convenient method in the modern era of ultra-sophisticated technology. While nasal endoscopy came into clinical practice in the late 1980s. It is the gold standard method for assessing the size of adenoids. It provides a three-dimensional picture and the lateral extension of adenoids can be assessed. So, reaching an accurate diagnosis is easier by nasal endoscopy.

\section{References}

1. Robb PR, Browning GG, Burton MJ, et al. The adenoid and adenoidectomy, Scott-Brown's otorhinolaryngology. Head and 
Neck surgery, vol. 1 7th ed., London: Hodder and Arnold; 2008. pp. 1094-1099.

2. Pederson PM. Adenoidectomy: an evaluation of the original technique. AMA Archiv Otolaryngol 1957;66(5):517-524. DOI: 10.1001/ archotol.1957.03830290023004.

3. Rubin RM. Effects of nasal airway obstruction on facial growth. Ear Nose Throat J 1987;66(5):212-219.

4. Lourenço EA, Lopes KC, Pontes Á, et al. Comparison between radiological and nasopharyngoscopic assessment of adenoid tissue volume in mouth breathing children. Braz J Otorhinolaryngol 2005;71(1):23-27. DOI: 10.1016/S1808-8694(15) 31280-5.

5. Wormald PJ, Prescott CA. Adenoids: comparison of radiological assessment methods with clinical and endoscopic findings. J Laryngol Otol 1992;106(04):342-344. DOI: 10.1017/S00222151 00119449.

6. Ysunza A, Pamplona MC, Ortega JM, et al. Video fluoroscopy for evaluating adenoid hypertrophy in children. Int J Pediatr Otorhinolaryngol 2008;72(8):1159-1165. DOI: 10.1016/j. ijporl.2008.03.022.

7. Kubba H, Bingham BJ. Endoscopy in the assessment of children with nasal obstruction. J Laryngol Otol 2001;115(05):380-384. DOI: 10.1258/0022215011907929.

8. Cassano $\mathrm{P}$, Gelardi M, Cassano M, et al. Adenoid tissue rhinopharyngeal obstruction grading based on fibre-endoscopic findings: a novel approach to therapeutic management. Int J Paediatric Otorhino Laryngol 2003;67(12):1303-1309. DOI: 10.1016/j.jporl.2003.07.018.

9. Mlynarek A, Tewfik MA, Hagr A, et al. Lateral neck radiography versus direct video rhinoscopy in assessing adenoid size. J Otolaryngol 2004;33(6):360-365. DOI: 10.2310/7070.2004.03074.

10. Orji FT, Okolugho NE, Ezeanolue BC. The role of adenoidal obstruction in the pathogenesis of otitis media with efficiency in Nigeries children. Nigerian J Med 2010;19(1):62-68.

11. Fujioka M, Young LW, Gridang BR. Radiographic evaluation of adenoidal size in children; adenoidal-nasopharyngeal ratio. Am J Radiol 1979;133(3):401-404. DOI: 10.2214/ajr.133.3.401.

12. Wright ED, Pearl AJ, Manoukian JJ. Laterally hypertrophic adenoids as a contributing factor in otitis media. Int J Paediat Otorhinolaryn 1998;45(3):207-214. DOI: 10.1016/S0165-5876(98)00113-X.

13. Cohen LM, Koltai PJ, Scott JR. Lateral cervical radiographs and adenoid size: do they correlate? Ear Nose Throat J 1992;71(12):638642. DOI: 10.1177/014556139207101207.

14. Yilmaz I, Caylakli F, Yilmazee C, et al. Correlation of diagnostic systems with adenoidal tissue volume: a blind prospective study. Int J Paediat Otorhinolaryn 2008;72(8):1235-1240. DOI: 10.1016/j. ijporl.2008.05.002.

15. Kinderman CA, Roithmann R, Netu JF. Sensitivity and specificity of nasal flexible fiberoptic endoscopy in the diagnosis of adenoid hypertrophy in children. Int J Peadiat Otolaryngol 2008;72(1):63-67. DOI: 10.1016/j.ijporl.2007.09.013. 